\title{
Substrato, temperatura de germinação e desenvolvimento pós-seminal de sementes de Dalbergia nigra
}

\author{
Antônio Carlos Silva de Andrade ${ }^{(1)}$, Tânia Sampaio Pereira(1), Marina de Jesus Fernandes ${ }^{(1)}$, \\ Ana Paula Martins Cruz ${ }^{(1)}$ e Amanda Silva da Rosa Carvalho( ${ }^{(1)}$
}

(1)Instituto de Pesquisas Jardim Botânico do Rio de Janeiro, Rua Pacheco Leão, no 915, CEP 22460-030 Rio de Janeiro, RJ. E-mail: candrade@jbrj.gov.br, tpereira@jbrj.gov.br, marina@jbrj.gov.br, acruz@jbrj.gov.br, amandasrcarvalho@yahoo.com.br

\begin{abstract}
Resumo - O objetivo deste trabalho foi definir o tipo de substrato e a temperatura mais adequada à germinação de sementes de Dalbergia nigra (Vell.) Fr. All. Ex Benth (jacarandá-da-bahia), e conhecer a morfologia de seu desenvolvimento pós-seminal e caracterizar as plântulas normais, o tipo de germinação e os padrões de anormalidade. As sementes foram semeadas nos substratos sobre papel, rolo de papel e sobre vermiculita, nas temperaturas constantes de $20,25,30$ e $35^{\circ} \mathrm{C}$ e alternadas de $20-30^{\circ} \mathrm{C}$ e $20-35^{\circ} \mathrm{C}$. O delineamento estatístico empregado foi o inteiramente casualizado (6x3), com quatro repetições de 50 sementes. Foram analisados os seguintes parâmetros: porcentagem de germinação normal (plântulas normais) e velocidade de emergência de plântulas. Os melhores resultados foram verificados nas temperaturas de $25^{\circ} \mathrm{C}$ e $20-30^{\circ} \mathrm{C}$, nos substratos sobre vermiculita e rolo de papel. Plântulas normais foram caracterizadas como faneroepígeas em relação ao tipo de germinação.
\end{abstract}

Termos para indexação: morfologia da plântula, sementes florestais nativas, jacarandá-da-bahia.

\section{Germination substrate, temperature and post-seminal development of Dalbergia nigra seeds}

\begin{abstract}
The objective of this work was to define the germination substrate of Dalbergia nigra (Vell.) Fr. All. Ex Benth (jacarandá-da-bahia), to evaluate the most appropriate temperature for its seeds germination, and to study its post-seminal morphology, showing normal and abnormal seedlings patterns. Seeds were sowed on filter paper, towel paper and vermiculite, using the constant temperatures of $20,25,30$ and $35^{\circ} \mathrm{C}$ as well as alternate temperatures of $20-30^{\circ} \mathrm{C}$ and $20-35^{\circ} \mathrm{C}$. The statistical design was completely randomized (6x3) with 50 seeds sowed in four replications in which the following parameters were analyzed: normal germination (normal seedlings) percentage and speed emergence index. The best results were obtained for temperatures of $25^{\circ} \mathrm{C}$ and $20-30^{\circ} \mathrm{C}$ in vermiculite and towel paper substrates. Normal seedlings were classified as faneroepigeal germination type.
\end{abstract}

Index terms: seedling morphology, native forest seeds, jacarandá-da-bahia.

\section{Introdução}

Dalbergia nigra (Vell.) Fr. All., conhecida popularmente como jacarandá-da-bahia, jacarandá-preto ou caviúna, é uma leguminosa (Papilionoideae) de porte arbóreo com características de planta semi-heliófita de ocorrência na Floresta Ombrófila Densa (Floresta Atlântica) (Lorenzi, 1992; Carvalho, 1994).

A exploração indiscriminada dessa espécie, em virtude da madeira de ótima qualidade, além da devastação de seu ambiente natural, ocasionou sua inclusão na lista de espécies da flora brasileira ameaçadas de extinção (Brasil, 1992b; IUCN, 1994). A necessidade de preservação da espécie, bem como de plantios de reflorestamento, tem despertado interesse pela cultura e estudos por parte de técnicos e pesquisadores (Carvalho, 1994).

Apesar do aumento dos dados de análise de sementes de espécies nativas, ainda há carência de informações sobre as condições ideais de germinação de muitas espécies. A análise é realizada por meio de um conjunto de procedimentos, padronizados pelas Regras para Análise de Sementes (Brasil, 1992a), e busca avaliar a qualidade quanto à composição do lote e capacidade germinativa para fins de semeadura. Tal padronização visa a uniformizar os resultados, permitindo a compara- 
ção entre diferentes laboratórios. A padronização desses métodos deve ser constantemente reavaliada mediante aplicação de testes de referência, de testes alternativos e da determinação de novas metodologias.

Com base nesses estudos, as Regras para Análise de Sementes são revisadas para espécies já relacionadas e para a incorporação de outras espécies (Formoso \& Andrade, 1988). Nas espécies florestais nativas, a padronização de métodos de análise de germinação é escassa, pois representa menos de $0,1 \%$ das prescrições e recomendações de sementes florestais nas Regras para Análise de Sementes (Figliolia et al., 1993). Há ausência de informações sobre a metodologia de germinação de sementes de jacarandá-da-bahia nas Regras para Análise de Sementes (Brasil, 1992a).

O teste de germinação, utilizado em laboratório para avaliar a qualidade da semente, é realizado sob condições de temperatura e substrato ideais para cada espécie. De acordo com Bewley \& Black (1994), a temperatura influencia a porcentagem final e a velocidade da germinação, afetando tanto a absorção de água pela semente quanto as reações bioquímicas que regulam o metabolismo envolvido nesse processo. As sementes são capazes de germinar sob ampla faixa de temperaturas, definida para cada espécie com uma temperatura máxima e uma mínima, acima e abaixo das quais a germinação não ocorre.

O substrato também apresenta influência nos testes de germinação, já que fatores como aeração, estrutura, capacidade de retenção de água, grau de infestação de patógenos, entre outros, podem variar de acordo com o tipo de material utilizado (Popinigis, 1985). O substrato deve manter proporção adequada entre a disponibilidade de água e aeração e não deve ser umedecido em excesso, para evitar que a película de água envolva completamente a semente e diminua a entrada e absorção de oxigênio (Villagomez et al., 1979). Portanto, a escolha do tipo de substrato deve ser feita de acordo com as exigências da semente em relação ao seu tamanho e formato (Brasil, 1992a).

Embora existam poucas informações sobre a influência da temperatura na germinação de sementes de jacarandá-da-bahia (Salomão et al., 1995; Ferraz-Grande \& Takaki, 2001), resultados observados apresentaram diferenças quanto à melhor temperatura para a germinação. Além disso, esses estudos avaliaram esta variável de forma isolada e não foram encontrados dados sobre a influência do substrato e de sua possível interação com a temperatura para a germinação de sementes dessa espécie.
Este trabalho teve como objetivo avaliar a influência de diferentes temperaturas e substratos na germinação de sementes de jacarandá-da-bahia, analisar a morfologia de seu desenvolvimento pós-seminal e caracterizar a plântula normal e os padrões de anormalidade.

\section{Material e Métodos}

Sementes de jacarandá-da-bahia foram obtidas a partir da coleta de frutos em estádio uniforme de maturação visual, provenientes de matrizes plantadas no Arboreto do Jardim Botânico do Rio de Janeiro. Os frutos foram levados ao Laboratório de Sementes do Jardim Botânico do Rio de Janeiro, onde permaneceram armazenados sob temperatura de $15^{\circ} \mathrm{C}$ até a montagem dos experimentos. Na obtenção de sementes limpas, os frutos foram beneficiados manualmente, eliminando-se sementes malformadas, abaixo do tamanho médio, e as que apresentavam danos superficiais causados pelo beneficiamento.

Os tratamentos, que consistiram das temperaturas e substratos, foram distribuídos em delineamento inteiramente casualizado, em esquema fatorial de $6 \times 3$. Foram utilizadas as temperaturas constantes de 20, 25, 30 e $35^{\circ} \mathrm{C}$ e alternadas de $20-30^{\circ} \mathrm{C}$ e $20-35^{\circ} \mathrm{C}\left( \pm 0,5^{\circ} \mathrm{C}\right)$, nos substratos sobre vermiculita, sobre papel e rolo de papel, previamente esterilizados. Nos substratos sobre vermiculita e sobre papel, os testes foram conduzidos em recipientes de plástico do tipo "gerbox". O substrato rolo de papel foi colocado no interior de sacos de plástico. Todos os tratamentos foram conduzidos em câmaras de germinação do tipo BOD, sob fotoperíodo de 10 horas de luz, com lâmpadas fluorescentes do tipo "luz do dia” (4x20 W), com densidade do fluxo radiante na altura dos recipientes de $90 \mu \mathrm{mol} \mathrm{m}{ }^{-2} \mathrm{~s}^{-1}$, medida com quantum radiômetro Li-Cor. Foram utilizadas quatro repetições de 50 sementes. Foram consideradas germinadas as sementes que produziram plântulas em perfeito estádio de desenvolvimento, de acordo com as Regras para Análise de Sementes (Brasil, 1992a). Com base nesse critério, foram avaliadas as variáveis: porcentagem de germinação e velocidade de emergência de plântulas, de acordo com Maguire (1962).

Os dados em porcentagem foram transformados em arc sen $(\% / 100)^{0,5}$, para normalização de sua distribuição, e submetidos à análise de variância. Foi utilizado o teste de Tukey (5\% de probabilidade) para comparação entre as médias, quando houve significância pelo teste F (Zar, 1999). 
Depois da determinação prévia do grau de umidade, peso de mil sementes e do número de sementes por quilograma (Brasil, 1992a), foi realizada, em dias alternados, a descrição morfológica durante o desenvolvimento pós-seminal. As ilustrações foram feitas com auxílio de estereomicroscópio ótico (5 x), equipado com câmara clara. Os critérios estabelecidos para caracterizar a plântula normal e os tipos de anormalidades basearam-se nas Regras para Análise de Sementes (Brasil, 1992a), utilizando-se a terminologia de Stearn (1983). O tipo de germinação foi classificado a partir dos estudos de Duke \& Polhill (1981), com modificações.

\section{Resultados e Discussão}

A determinação das características físicas revelou sementes com grau de umidade de $26,88 \%$, peso de mil sementes de $1.711,3$ g e 584,4 sementes por quilograma.

A emergência da radícula iniciou-se entre cinco e oito dias da germinação (Figura 1 a). O eixo hipocótiloradícula é sinuoso e esverdeado, não sendo evidente, neste estádio, a delimitação do colo e raiz (Figura 1 b). Os cotilédones verdes emergem dos restos seminais, exibindo o sinus cotiledonar auriculado (Figura $1 \mathrm{c}, \mathrm{e}$ ). O hipocótilo é robusto, cilíndrico, verde e sinuoso aos 8-12 dias da germinação e pode apresentar rugosidade quando muito sinuoso (Figura 1 e); a região do colo é estreita, destacada da raiz principal, sendo esta vigorosa e cilíndrica (Figura 1 d, e, f) com zona pilífera nítida e limitada à base da raiz. Os cotilédones subcrassos, côncavo-convexos, reniformes e verdes, quando livres dos restos seminais (Figura $1 \mathrm{f}, \mathrm{g}, \mathrm{h}, \mathrm{i}$ ), iniciam a expansão e expõem a plúmula aos 12-14 dias.

A plântula normal aos 13-15 dias da germinação apresenta a raiz principal fina e cilíndrica, com zona pilífera limitada ao terço inicial, junto ao colo, com ou sem raízes secundárias; o hipocótilo é cilíndrico, verde, delgado e apresenta indumento hirsuto-piloso a partir do terço médio até o epicótilo. Cotilédones totalmente expandidos expõem a face convexa ou sofrem rápida abscisão do hipocótilo, o que evidencia a germinação faneroepigeal. O epicótilo eleva o eófilo, que compreende um par de folhas compostas, plurifolioladas, paripenadas, com nervação central bem marcada (Figura $1 \mathrm{j}$ ).

A plântula normal, descrita por Brasil (1992a), deve ter todas as suas estruturas essenciais presentes e saudáveis. Quando este padrão não ocorre, temos plântulas anormais, resultantes de tratamento a que as sementes foram submetidas, de formação congênita, ou da idade da semente.

Os tipos de anormalidade mais freqüentes, encontrados durante o processo de germinação de Dalbergia nigra, são o apodrecimento do hipocótilo e raiz principal, em plântulas com o epicótilo saudável, e lesões ou deformações no epicótilo e eófilo, em virtude do uso das caixas de plástico com tampa, com altura reduzida em relação à altura da plântula.

Pode-se citar, ainda, o total apodrecimento da plântula nos estádios iniciais do desenvolvimento pós-seminal (Figuras 2 a, b, c) ou em estádios mais avançados (Figuras $2 \mathrm{~d}-\mathrm{j}$ ).

Anormalidades associadas ao hipocótilo, como torções (Figuras $2 \mathrm{i}-0$ ), enovelamento e quebra (Figura 2 h), ou redução com lesões (Figura 2 f), ou plântulas contendo lesões profundas (Figuras 2 i, l), são freqüentes no desenvolvimento de Dalbergia nigra.

A má-formação ou deterioração da raiz são as anormalidades mais freqüentes. Tais anomalias podem se apresentar como a redução total com apodrecimento do sistema radicular (Figura 2 b), ou plântulas com raízes truncadas (Figuras 2 e, n), bifurcadas e involuídas (Figura $2 \mathrm{~g}$ ), ou filiformes e deterioradas (Figura $2 \mathrm{f}$ ).

Outra anormalidade freqüente são raízes fracas, sem função fixadora (Figuras a-d). O sistema radicular pode, ainda, ter aparência normal, porém o ataque de fungos provoca a deterioração das raízes, inviabilizando o desenvolvimento da plântula (Figuras 2 i).

As deformações do epicótilo são menos freqüentes, porém são definitivas na análise das plântulas. Tais anormalidades podem ser facilmente reconhecidas na formação congênita, que induz à plúmula malformada, reduzida ou descorada, desenvolvendo estruturas foliares deformadas na plântula (Figuras 2 a, b, e), ou epicótilos torcidos, quebrados ou que apresentam deformações dos folíolos (Figuras 2 c, d).

Nos cotilédones, a anormalidade mais freqüente está associada ao apodrecimento ou à deformação total ou parcial, sendo entretanto considerada de menor importância para a análise de normalidade, em vista do caráter efêmero dessas estruturas para a germinação da espécie.

Os resultados de porcentagem de germinação normal são apresentados na Tabela 1. A partir da interação significativa dos substratos e temperaturas para esta variável, verificou-se que, na temperatura de $35^{\circ} \mathrm{C}$, os substratos rolo de papel e sobre vermiculita apresenta- 
ram valores superiores aos encontrados para o substrato sobre papel. As demais temperaturas não apresentaram diferenças entre os substratos testados. Na análise das temperaturas de cada um dos substratos, verificou-se que, nos substratos sobre vermiculita e rolo de papel, as temperaturas não apresentaram diferenças entre si, exceto em relação à temperatura de $35^{\circ} \mathrm{C}$, inferior às demais. No substrato sobre papel, à semelhança do encontrado nos demais substratos, a temperatura de $35^{\circ} \mathrm{C}$ foi a que apresentou o menor valor de germinação, inferior a todas as temperaturas testadas. Nesse substrato, os maiores valores de germinação foram verificados nas temperaturas de $20,20-30,25$ e $20-35^{\circ} \mathrm{C}$.

Em relação aos valores de velocidade de emergência de plântulas (Tabela 2), verificou-se, com base na interação significativa dos substratos e temperaturas, que na temperatura de $20-30^{\circ} \mathrm{C}$ o substrato sobre vermiculita apresentou valores superiores aos encontrados nos substratos rolo de papel e sobre papel. Nas demais temperaturas, não houve diferença entre os substratos testados. Na análise das temperaturas para cada um dos substratos, verificou-se que, no substrato sobre vermiculita, a temperatura de $20-30^{\circ} \mathrm{C}$ foi superior às demais temperaturas testadas. No substrato sobre papel, as temperaturas de $25,30,20-30,20$ e $20-35^{\circ} \mathrm{C}$ não apresentaram diferenças entre si, sendo superiores à temperatura de $35^{\circ} \mathrm{C}$. No substrato rolo de papel, as temperaturas de 30 e $25^{\circ} \mathrm{C}$ foram superiores às demais, exceto para a temperatura de $20-30^{\circ} \mathrm{C}$.

Nos estudos relacionados à metodologia de germinação de espécies florestais, Oliveira et al. (1989) recomendaram o uso de temperaturas alternadas, já que essas simulariam o ambiente natural de florestas, onde as flutuações de temperaturas ocorrem, principalmente, pela

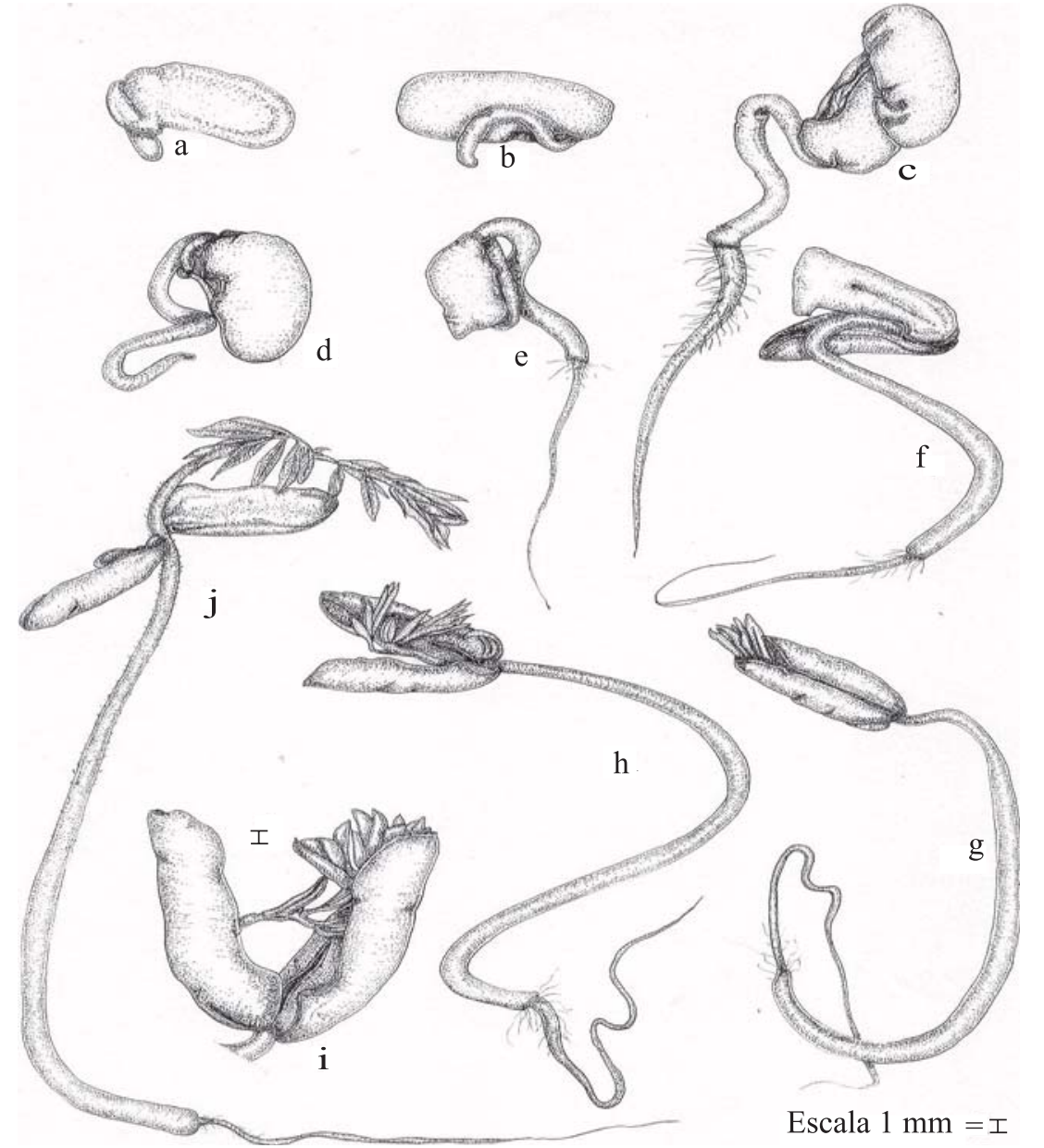

Figura 1. Fases iniciais do desenvolvimento pós-seminal de Dalbergia nigra (a-f), considerando-se a emergência da plúmula (g-i) e a plântula normal (j). 
abertura de clareiras que estimulam a germinação de espécies pioneiras. Em alguns casos, a alternância de temperaturas aumentou consideravelmente a germinação em determinadas espécies, como o verificado em sementes de Syzygium aromaticum (Maeda et al., 1991) e Torresia acreana (Albrecht et al., 1986). Todavia, a alternância de temperaturas pode inibir parcialmente o desenvolvimento da germinação conforme Carneiro \& Pires (1983) em sementes de Ricinus communis, e Andrade \& Pereira (1994) de Cedrela odorata. Neste trabalho, os resultados demonstraram que as sementes de Dalbergia nigra não possuem exigência de alternância de temperatura, para acelerar ou iniciar o processo germinativo, uma vez que tanto temperaturas constantes quanto alternadas apresentaram valores elevados de germinação e de velocidade de emergência de plântulas. Tais resultados demonstraram que suas se- mentes podem germinar na sombra da vegetação, onde as temperaturas sofrem pouca variação diária, e em clareiras, onde a variação entre as temperaturas mínima e máxima pode ser superior a $15^{\circ} \mathrm{C}$ (Vázquez-Yanes \& Orozco-Segovia, 1996).

Embora a temperatura ótima para a germinação de sementes de espécies tropicais encontre-se entre 20 e $35^{\circ} \mathrm{C}$ (Brasil, 1992a), os resultados observados na temperatura de $35^{\circ} \mathrm{C}$ para porcentagem de germinação e para velocidade de emergência de plântulas indicaram que as sementes de $D$. nigra não suportaram temperaturas tão elevadas. Independentemente do substrato, os maiores valores de germinação e de velocidade de emergência foram alcançados em temperaturas entre 20 e $30^{\circ} \mathrm{C}$, além das temperaturas alternadas de $20-30$ e $20-35^{\circ} \mathrm{C}$.

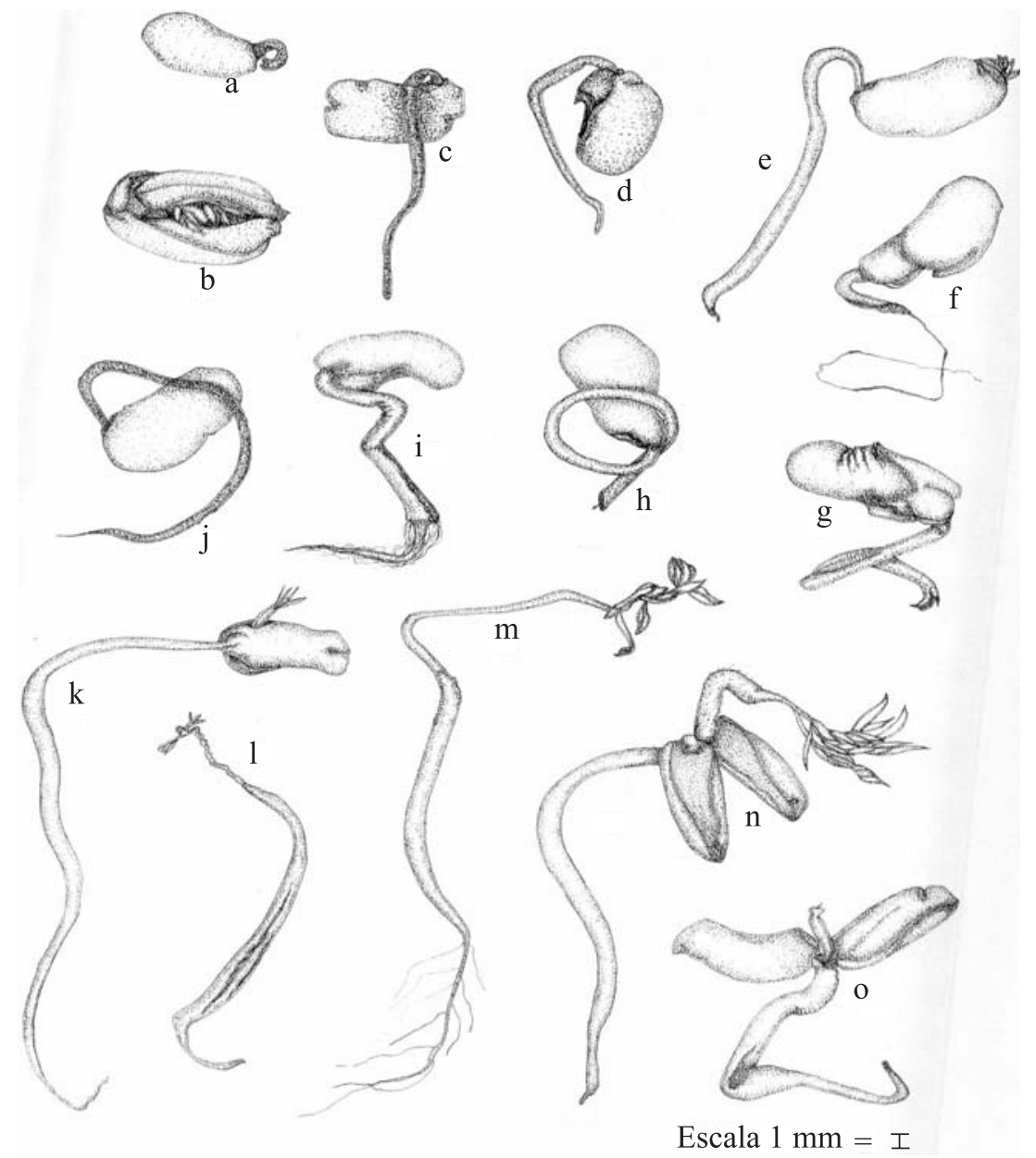

Figura 2. Tipos mais freqüentes de anormalidades, durante as fases de protrusão da radícula (a-j) e do desenvolvimento da plântula (k-0) de Dalbergia nigra. 
Os resultados concordam com os obtidos para essa mesma espécie, por Salomão et al. (1995), em que sementes provenientes de três árvores apresentaram os valores mais altos de germinação sob temperatura alternada de $20-30^{\circ} \mathrm{C}$, e por Ferraz-Grande \& Takaki (2001), em que a temperatura constante de $30,5^{\circ} \mathrm{C}$ foi considerada ótima, embora a espécie apresente ampla faixa de temperaturas em que a germinação ocorre.

Os substratos testados influenciaram sensivelmente a germinação de sementes de D. nigra. É provável que a capacidade de retenção da água de cada substrato, aliada às características intrínsecas que regulam o fluxo de água para as sementes, possa ter influenciado os resultados. A variação na disponibilidade de água dos substratos, fator comum nesse tipo de trabalho (Peterson \& Cooper, 1979), causa freqüentemente redução nos valores de germinação de sementes, provocando diferenças entre médias. Dos substratos utilizados, o sobre papel foi o que mostrou menor capacidade de retenção de água, que se apresentou como o de menores médias de germinação e vigor.

Os maiores valores de germinação e de velocidade de emergência de plântulas foram encontrados no substrato sobre vermiculita. Comportamento semelhante foi verificado por Pereira \& Andrade (1994) em sementes de maracujá, em que a germinação apresentou valores superiores. Pinto (1987) atribuiu a alta capaci-

Tabela 1. Germinação normal (\%), obtida na contagem final (30 dias), de acordo com as temperaturas e substratos avaliados em sementes de Dalbergia nigra ${ }^{(1)}$.

\begin{tabular}{lcccccc}
\hline Substrato & $20^{\circ} \mathrm{C}$ & $25^{\circ} \mathrm{C}$ & $30^{\circ} \mathrm{C}$ & $35^{\circ} \mathrm{C}$ & $20-30^{\circ} \mathrm{C}$ & $20-35^{\circ} \mathrm{C}$ \\
\hline Sobre vermiculita & $70 \mathrm{Aa}$ & $83 \mathrm{Aa}$ & $64 \mathrm{Aa}$ & $24 \mathrm{Ba}$ & $73 \mathrm{Aa}$ & $73 \mathrm{Aa}$ \\
Sobre papel & $75 \mathrm{Aa}$ & $70 \mathrm{Aa}$ & $46 \mathrm{Ba}$ & $10 \mathrm{Cb}$ & $74 \mathrm{Aa}$ & $60 \mathrm{ABb}$ \\
Rolo de papel & $74 \mathrm{Aa}$ & $74 \mathrm{Aa}$ & $82 \mathrm{Aa}$ & $22 \mathrm{Ca}$ & $81 \mathrm{Aa}$ & $45 \mathrm{Bc}$ \\
\hline
\end{tabular}

(1)Médias seguidas pelas mesmas letras, minúsculas nas colunas e maiúsculas nas linhas, não diferem entre si pelo teste de Tukey a $5 \%$ de probabilidade.

Tabela 2. Velocidade de emergência (por dia), de acordo com as temperaturas e substratos avaliados em sementes de Dalbergia nigra ${ }^{(1)}$.

\begin{tabular}{lllllll}
\hline Substrato & $20^{\circ} \mathrm{C}$ & $25^{\circ} \mathrm{C}$ & $30^{\circ} \mathrm{C}$ & $35^{\circ} \mathrm{C}$ & $20-30^{\circ} \mathrm{C}$ & $20-35^{\circ} \mathrm{C}$ \\
\hline Sobre vermiculita & $0,058 \mathrm{CDa}$ & $0,081 \mathrm{Ba}$ & $0,082 \mathrm{Ba}$ & $0,047 \mathrm{Da}$ & $0,115 \mathrm{Aa}$ & $0,070 \mathrm{BCa}$ \\
Sobre papel & $0,071 \mathrm{Aa}$ & $0,083 \mathrm{Aa}$ & $0,076 \mathrm{Aa}$ & $0,059 \mathrm{Ba}$ & $0,075 \mathrm{Ab}$ & $0,063 \mathrm{Aa}$ \\
Rolo de papel & $0,056 \mathrm{Ca}$ & $0,082 \mathrm{ABa}$ & $0,086 \mathrm{Aa}$ & $0,057 \mathrm{Ca}$ & $0,077 \mathrm{ABCb}$ & $0,061 \mathrm{BCa}$ \\
\hline & \\
(1) Médias seguidas pelas mesmas letras, minúsculas nas colunas e maiús- \\
culas nas linhas, não diferem entre si pelo teste de Tukey a $5 \%$ de \\
probabilidade.
\end{tabular}

dade de retenção de água e as condições adequadas de aeração da vermiculita às suas propriedades físico-químicas. Tais características podem ter contribuído para o aumento do porcentual germinativo de sementes de Dalbergia nigra nesse substrato, em comparação com os demais.

A avaliação do processo germinativo em dias consecutivos permitiu a confecção das curvas de germinação cumulativas (Figura 3). Verificou-se que a máxima germinação foi obtida entre 15 e 18 dias; a germinação iniciou-se entre o 8o e o 11음 dias para as temperaturas que apresentaram maior velocidade de germinação (30, 25 e $20-30^{\circ} \mathrm{C}$ ), independentemente do substrato testado. Nessas temperaturas, cerca de $50 \%$ de plântulas haviam se formado por completo, depois de 12 dias de condução do experimento. A partir de 21 dias, as curvas de germinação começaram a se estabilizar, e não foi mais observada a germinação.

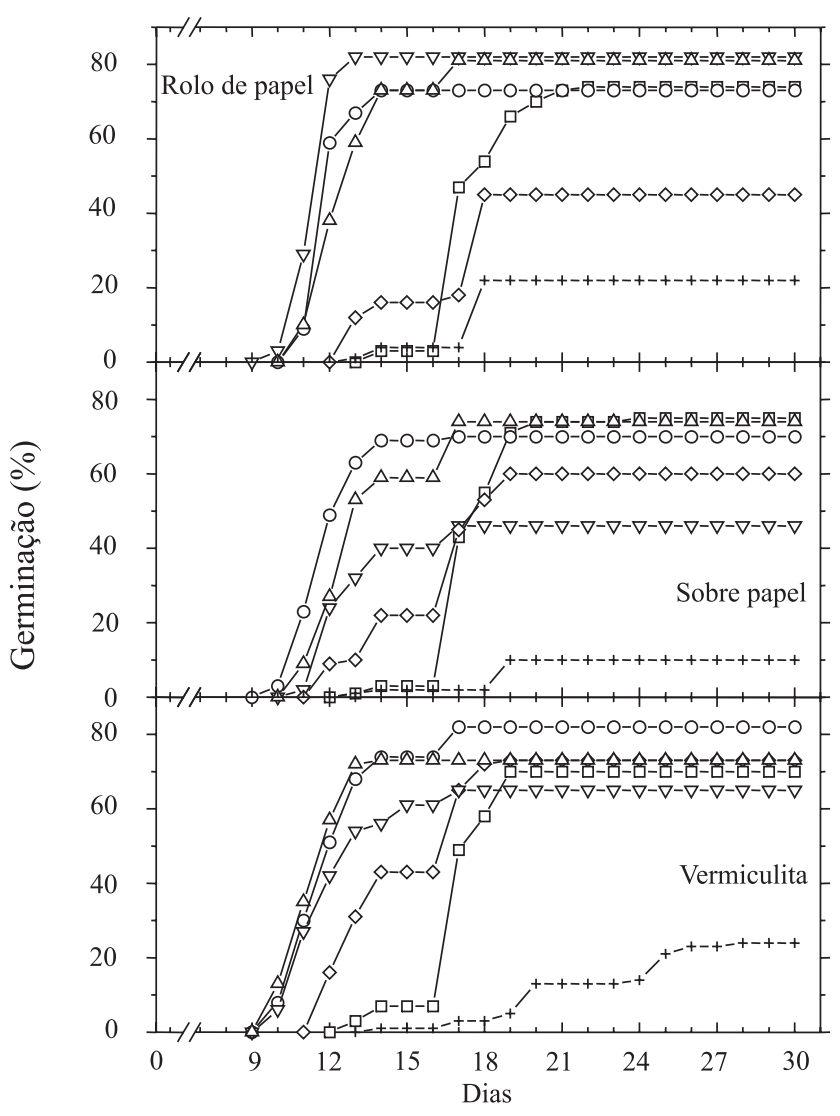

Figura 3. Germinação cumulativa (porcentagem de plântulas normais) de sementes de Dalbergia nigra, nos substratos rolo de papel, sobre papel e sobre vermiculita, nas temperaturas de $20^{\circ} \mathrm{C}(\square), 25^{\circ} \mathrm{C}(\bigcirc), 30^{\circ} \mathrm{C}(\nabla), 35^{\circ} \mathrm{C}(+), 20-30^{\circ} \mathrm{C}(\triangle)$ e $20-35^{\circ} \mathrm{C}(\diamond)$. 


\section{Conclusões}

1. A germinação de Dalbergia nigra é do tipo faneroepigeal; os cotilédones apresentam função de reserva e sofrem rápida abscisão do hipocótilo.

2. As temperaturas constantes entre 20 e $30^{\circ} \mathrm{C}$, as temperaturas alternadas de $20-30^{\circ} \mathrm{C}$ e $20-35^{\circ} \mathrm{C}$ e o substrato sobre vermiculita são os mais adequados para a germinação de sementes de Dalbergia nigra.

\section{Agradecimentos}

À Faperj e ao CNPq, pela concessão de bolsas.

\section{Referências}

ALBRECHT, J.M.F.; ALBUQUERQUE, M.C.F.; SILVA, F.S.M. Influência da temperatura e do substrato na germinação de sementes de cerejeira. Revista Brasileira de Sementes, v.8, p.49-55, 1986.

ANDRADE, A.C.S.; PEREIRA, T.S. Efeito do substrato e da temperatura na germinação e no vigor de sementes de cedro - Cedrela odorata L. (Meliaceae). Revista Brasileira de Sementes, v.16, p.34-40, 1994.

BEWLEY, D.D.; BLACK, M. Seeds: physiology of development and germination. New York: Plenum, 1994. 467p.

BRASIL. Ministério da Agricultura e Reforma Agrária. Regras para análise de sementes. Brasília, 1992a. 365p.

BRASIL. Portaria n.006/92-N, de 15 de janeiro de 1992. Lista oficial de espécies da flora brasileira ameaçadas de extinção. Diário Oficial da República Federativa do Brasil, Brasília, 23 jan. 1992b. p.870872.

CARNEIRO, J.W.P.; PIRES, J.C. Influência da temperatura e do substrato na germinação de sementes de mamona. Revista Brasileira de Sementes, v.5, p.127-131, 1983.

CARVALHO, P.E.R. Espécies florestais brasileiras: recomendações silviculturais, potencialidades e uso da madeira. Colombo: Embrapa-CNPF; Brasília: Embrapa-SPI, 1994. 638p.

DUKE, J.A.; POLHILL, R.M. Seedlings of Leguminosae. In: POLHILL, R.M.; RAVEN, P.H. (Ed.). Advances in legume systematics. London: Kew Royal Botanical Garden, 1981. v.2, p.941-949.

FERRAZ-GRANDE, F.G.A.; TAKAKI, M. Temperature dependent seed germination of Dalbergia nigra Allem (Leguminosae). Brazilian Archives of Biology and Technology, v.44, p.401-404, 2001.

FIGLIOLIA, M.B.; OLIVEIRA, E.C.; PIÑA-RODRIGUES, F.C.M. Análise de sementes. In: AGUIAR, I.B.; PIÑA-RODRIGUES,
F.C.M.; FIGLIOLIA, M.B. (Coord.). Sementes florestais tropicais. Brasília: Abrates, 1993. p.37-74.

FORMOSO, A.M.T.; ANDRADE, R.N. Qualidade de sementes de hortaliças. In: ENCONTRO DE HORTALIÇAS DA REGIÃO SUL, 1988, Santa Maria. Anais. Santa Maria: Universidade Federal de Santa Maria, 1988. p.73-80.

IUCN. Red list categories. Switzerland: Gland, 1994. 28p.

LORENZI, H. Árvores brasileiras: manual de identificação de plantas arbóreas nativas do Brasil. São Paulo: Plantarum, 1992. 368p.

MAEDA, J.A.; BOVI, M.L.A.; BOVI, O.A.; LAGO, A.A. do. Germinação de sementes de craveiro-da-índia: efeito de temperatura, polpa do fruto e tratamento fungicida. Pesquisa Agropecuária Brasileira, v.26, p.893-899, 1991.

MAGUIRE, J.D. Speed of germination aid selection and evaluation for seedling emergence and vigour. Crop Science, v.2, p.176-177, 1962.

OLIVEIRA, E.C.; PIÑA-RODRIGUES, F.C.M.; FIGLIOLIA, M.B. Propostas para a padronização de metodologias em análise de sementes florestais. Revista Brasileira de Sementes, v.11, p.142, 1989.

PEREIRA, T.S.; ANDRADE, A.C.S. Germinação de Psidium guajava L. e Passiflora edulis S. - efeito da temperatura, do substrato e morfologia do desenvolvimento pós-seminal. Revista Brasileira de Sementes, v.16, p.58-62, 1994.

PETERSON, J.R.; COOPER, P.G. Some considerations of water in the germination test. Seed Science and Technology, v.7, p.329340, 1979.

PINTO, J.R. Perdas e movimento de P, K, Ca e Mg em um solo de tabuleiro costeiro tratado com vermiculita expandida. Recife: [s.n.], 1987. 45p.

POPINIGIS, F. Fisiologia da semente. Brasília: Agiplan, 1985. 128p.

SALOMÃO, A.N.; EIRA, M.T.S.; CUNHA, R. The effect of temperature on seed germination of four Dalbergia nigra Fr. Allem. - Leguminosae trees. Revista Árvore, v.19, p.588-594, 1995.

STEARN, W.T. Botanical latin. London: David and Charles, 1983. 566p.

VÁZQUEZ-YANES, C.; OROZCO-SEGOVIA, A. Physiological ecology of seed dormancy and longevity. In: MULKEY, S.S.; CHAZDON, R.L.; SMITH, A.P. (Ed.). Tropical forest plant ecophysiology. London: Chapman and Hall, 1996. p.535-558.

VILLAGOMEZ, Y.; VILLASENOR, R.; SALINAS, J.R. Lineamiento para el funcionamiento de un laboratorio de semillas. Mexico: INIF, 1979. 23p. (Boletín divulgativo, 48).

ZAR, J.H. Biostatistical analysis. New Jersey: Prentice Hall, 1999. 662 p.

Recebido em 23 de fevereiro de 2005 e aprovado em 20 de julho de 2005 